\title{
PRODUÇÃO E CARACTERIZAÇÃO DE BIOPOLÍMEROS DE INTERESSE INDUSTRIAL OBTIDOS A PARTIR DE FUNGOS ISOLADOS DO SEMIÁRIDO NORDESTINO
}

\author{
Gláucia Lais Pereira Lima Neco; ${ }^{1}$ Sandra Aparecida Assis²; \\ 1. Bolsista FAPESB, Graduando em Farmácia, Universidade Estadual de Feira de Santana, e-mail: \\ glaucialaisneco@hotmail.com \\ 2. Orientador, Departamento de Saúde, Universidade Estadual de Feira de Santana, e-mail: \\ sandrinhaassis@yahoo.com.br
}

PALAVRAS-CHAVE: Micro-organismos; semi-árido; Exopolissacarídeos.

\section{INTRODUÇÃO}

Uma variedade de produtos com aplicação tecnológica pode ser obtida a partir de micro-organismos. No Brasil, o semi-árido baiano apresenta grande diversidade de micro-organismos ainda não explorados, que podem ser utilizados como agentes biológicos para prospecção biotecnológica. Dentre as várias ferramentas ou sistemas utilizados pela biotecnologia, os micro-organismos têm destaque (MELO, 2005).

Os polissacarídeos são polímeros naturais, constituídos de um único tipo ou diferentes tipos de monossacarídeos, e embora estejam presentes em todos os seres vivos, a maior diversidade encontra-se no reino microbiano. Os polissacarídeos constituem um grupo de compostos abundantes e relevantes na biosfera, temos como exemplo, celulose e amido nos vegetais e glicogênio nos animais (LEHNINGER, 2002; GUIMARÃES et al., 2009).

Os polissacarídeos podem ser classificados como exopolissacarídeos (EPS) ou glucanas. Os EPS são metabólitos secundários produzidos durante a fase estacionária do crescimento microbiano, definidos por polissacarídeos extracelulares produzidos por grupos de bactérias e fungos (SUTHERLAND, 1998). Os polissacarídeos encontrados na parede celular de fungos são denominados glucanas, que são polímeros de glicose vastamente distribuídos na natureza e classificados de acordo com o tipo de ligação glicosídica - $\alpha, \beta$ - da cadeia principal (SILVA et al., 2006).

Vários exopolissacarídeos produzidos por micro-organismos ainda não foram adequadamente explorados e somente poucos têm sido produzidos em larga escala. Durante a produção dos exopolissacarídeos pelos micro-organismos, há parâmetros que podem influenciar no rendimento e na composição monossacarídica dessas moléculas, (SOUZA, 2004).

Polissacarídeos derivados de micro-organismos apresentam algumas vantagens de obtenção em relação às demais espécies, tais como: a não dependência das condições climáticas, maior rapidez na obtenção do produto acabado, o fato de poder utilizar matérias primas regionais e a necessidade de um menor espaço físico das instalações (ERNANDES et al., 2005).

\section{MATERIAIS E MÉTODOS}

Foram utilizados micro-organismos isolados e identificados, provenientes do Laboratório de Enzimologia (LAEN), da Universidade Estadual de Feira de Santana, e mantidos em estufa a $28^{\circ} \mathrm{C}$, até início da fermentação.

\section{Condicões de cultivo e extração}

Os micro-organismos foram inoculados em placa de Petri contendo meio YM sólido (Composição: extrato de levedura 3,0 g/L; extrato de malte 3,0 g/L; peptona de 
carne $5,0 \mathrm{~g} / \mathrm{L}$; glucose $10,0 \mathrm{~g} / \mathrm{L}$ e ágar $15,0 \mathrm{~g} / \mathrm{L}$ ) sob temperatura de refrigeração e cultivado em estufa de crescimento a $28{ }^{\circ} \mathrm{C}$. Após esse período de crescimento, alçadas do micro-organismo foram inoculados em solução salina $0,45 \%$ até alcançar a absorbância de aproximadamente $10^{7} \mathrm{UFC} / \mathrm{mL}$. Após isso, $10 \mathrm{ml}$ deste inoculo foram acrescentado em $100 \mathrm{ml}$ de meio YM líquido contendo extrato de levedura 3,2g/L, extrato de malte $3,0 \mathrm{~g} / \mathrm{L}$, peptona $5,0 \mathrm{~g} / \mathrm{L}$, glicose $10,0 \mathrm{~g} / \mathrm{L}$, fosfato de potásio monobásico $\left(\mathrm{KH}_{2} \mathrm{PO}_{4}\right)$, fosfato de potássio dibásico $\left(\mathrm{K}_{2} \mathrm{HPO}_{4}\right)$ 2,0 $\mathrm{g} / \mathrm{L}$, fosfato de magnésio heptahidratado $\left(\mathrm{MgSO}_{4}\right)$ 2,7 g/L. A fermentação ocorreu em shaker durante 5 dias, a $100 \mathrm{rpm}$ e $28^{\circ} \mathrm{C}$. Após a fermentação foi realizada centrifugação e a biomassa foi seca em estufa a $50^{\circ} \mathrm{C}$ até se obter peso constante. $\mathrm{O}$ sobrenadante foi utilizado para a obtenção de exopolissacarídeos, sendo adicionado etanol absoluto na proporção de 3:1 (etanol/sobrenadante), e conservado a $4^{\circ} \mathrm{C}$ por 24 horas, para precipitar os polissacarídeos.

\section{Processo de purificacão}

Para a purificação do exopolissacarídeo e da biomassa adicionou-se 10 volumes de $\mathrm{NaoH} 0,1 \mathrm{M}$ em $0,300 \mathrm{~g}$ de polissacarídeo. Foram utilizados nove tubos de ensaio devidamente identificados, incubados em banho-maria com temperaturas e tempo segundo o planejamento experimental Dohlert (tempo: 60, 90, 120, 150, 180 minutos; temperatura: $50^{\circ} \mathrm{C}, 70^{\circ} \mathrm{C}$ e $90^{\circ} \mathrm{C}$ ). Depois da incubação, as amostras foram centrifugadas em 10.000rpm por 10 minutos. O sobrenadante foi identificado como fração álcali solúvel e o precipitado como a fração álcali insolúvel. As amostras foram secos a $55^{\circ} \mathrm{C}$ por $24 \mathrm{~h}$ até atingir peso constante.

\section{Análise estatística}

Após obtenção dos resultados, os mesmos foram analisados através da Análise de Variância (ANOVA) através do programa Statistica 7.0 (StatSoft, Inc., Tulsa, USA), para indicar as variáveis com efeitos estatisticamente significativos $(p<0,05)$ e o ajuste do modelo aos dados experimentais.

\section{RESULTADOS E DISCUSSÃO}

Os resultados mostraram, que a partir do micro-organismo Cryptococcus liquefaciens (302) obteve-se uma produção total de 21,87 gramas de exopolissacarídeo e 14,93 gramas de biomassa em três litros de inoculo (proporção de 0,729 g/100mL e $0,498 \mathrm{~g} / 100 \mathrm{~mL}$ respectivamente), já o micro-organismo Rhodotorula orizycola (D2T61) apresentou uma produção total de 31,11 gramas de exopolissacarídeo e 14,75 gramas de biomassa em quatro litros de inoculo (proporção de 0,778 g/100mL e 0,369 g/100mL respectivamente). Como mostra a Figura 1, a produção de exopolissacarídeo e da biomassa, foram quantificados para cada $100 \mathrm{~mL}$ de meio YM líquido.

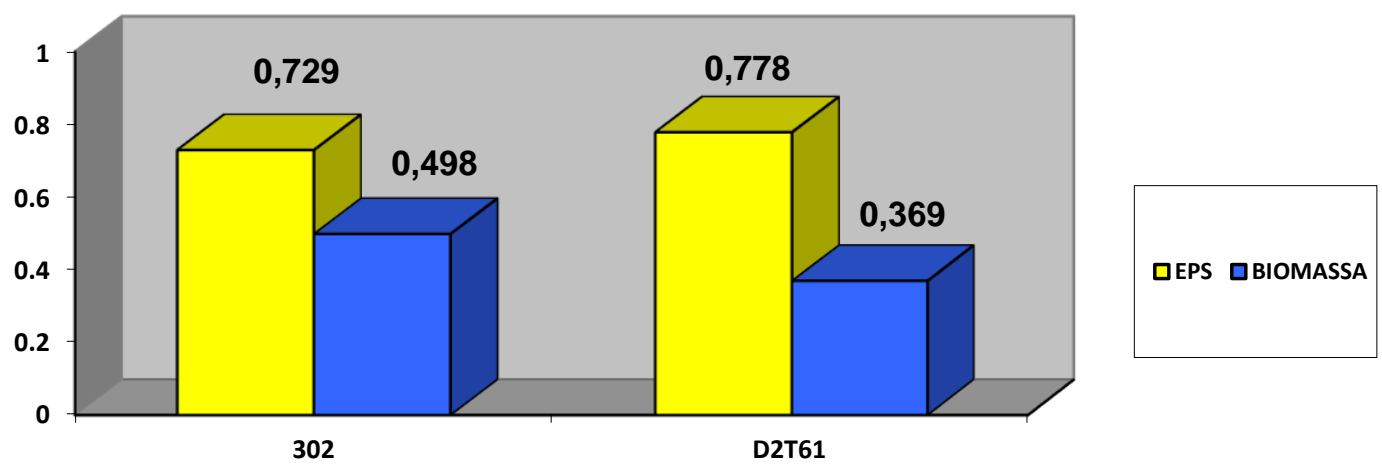

Gráfico 1: Produção de polissacarídeos a partir dos micro-organismos estudados (Cryptococcus liquefaciense, Rhodotorula orizycola), na proporção de g/100mL). 
O objetivo da purificação é a obtenção do material desejado, com as características e as suas funções preservadas, eliminando as substâncias indesejadas, que resultaram da fermentação (DINI, 2010).

A partir dos resultados do micro-organismo Cryptococcus liquefaciense foram plotados os gráficos de superfície de resposta e de curvas de níveis (Figura 1) aonde se pode visualizar que a produção ótima em temperaturas de $45^{\circ} \mathrm{C}$ a $95^{\circ} \mathrm{C}$, em tempos variando de 40 a 120 minutos. $\mathrm{O}$ valor de $\mathrm{R}^{2}$ obtido é 0,98 (Tabela 1), indicando que 98\% dos resultados são explicados pelo modelo experimental. O teste $\mathrm{F}$, mostrou que o modelo está bem ajustado, uma vez que o valor de F calculado da falta de ajuste $(0,19)$ é bem menor do que F tabelado $(18,81)$. De acordo com o nível de confiança de $95 \%$, a regressão correspondente é significativa, sendo que o $\mathrm{F}$ calculado $=31,73$ é maior que $\mathrm{F}$ tabelado $=9,01$.
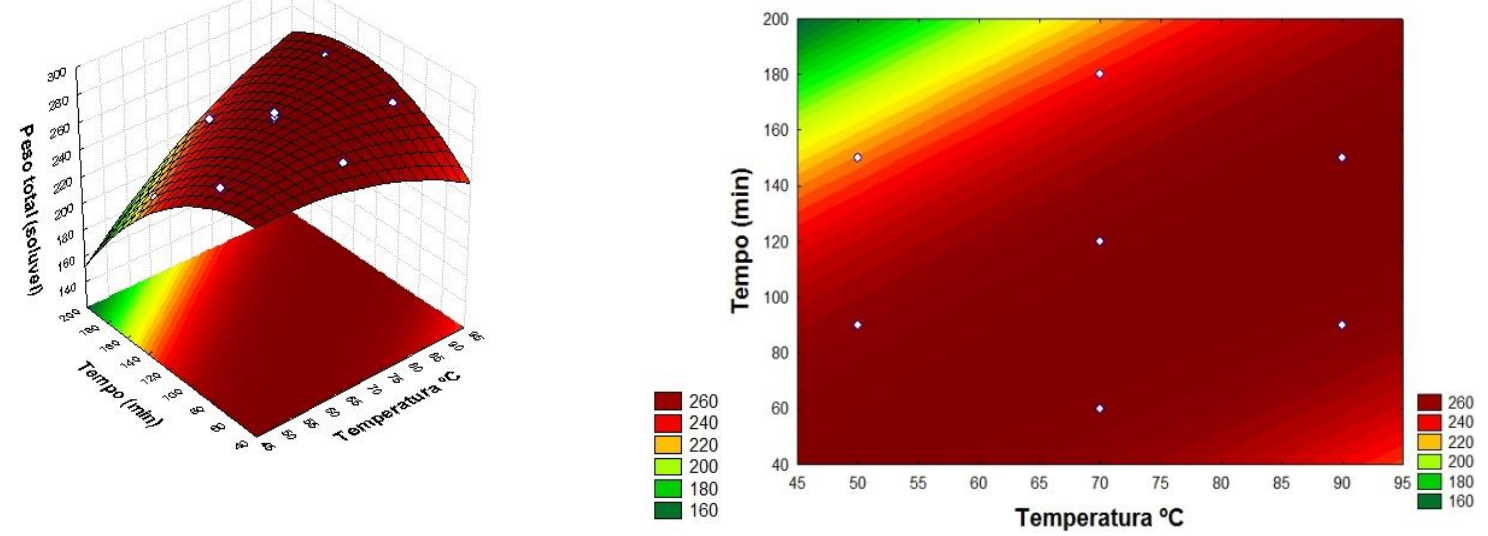

Figura 1: Gráfico superfície de resposta e curva de níveis - Influência do tempo e da temperatura na purificação da fração solúvel do exopolissacarídeo do micro-organismo Cryptococcus liquefaciens.

Tabela 1: Análise de variância (ANOVA) para purificação do exopolissacarídeo do micro-organismo Cryptococcus liquefaciens

TABELA DA ANOVA

\begin{tabular}{|c|c|c|c|c|c|c|}
\hline & SQ & gl & QM & Fcal & Ftab 5\% & $\mathrm{R}^{2}$ \\
\hline Regressão & 2441,83 & 5 & 488,3667 & 31,73 & 9,01 & 0,98 \\
\hline Residuo & 46,17 & 3 & 15,38889 & & & \\
\hline Ajuste & 4,17 & 1 & 4,166667 & 0,19 & 18,81 & \\
\hline Erro & 42,00 & 2 & 21 & & & \\
\hline Total & 2488,00 & & & & & \\
\hline
\end{tabular}

FONTE: Autora

Em relação ao micro-organimo Rhodotorula orizycola. A partir dos resultados foram plotados os gráficos de superfície de resposta e de curvas de níveis (Figura 2) aonde se pode visualizar que a produção ótima em temperaturas de $45^{\circ} \mathrm{C}$ a $75^{\circ} \mathrm{C}$, em tempos inferiores a 120 minutos. $\mathrm{O}$ valor de $\mathrm{R}^{2}$ obtido é 0,98 (Tabela 2), indicando que $98 \%$ dos resultados são explicados pelo modelo experimental. O teste $\mathrm{F}$, mostrou que o modelo está bem ajustado, uma vez que o valor de F calculado da falta de ajuste $(0,64)$ é bem menor do que F tabelado (18,81). De acordo com o nível de confiança de $95 \%$, a regressão correspondente é significativa, sendo que o $\mathrm{F}$ calculado $=43,05$, é maior que $\mathrm{F}$ tabelado $=9,01$. 

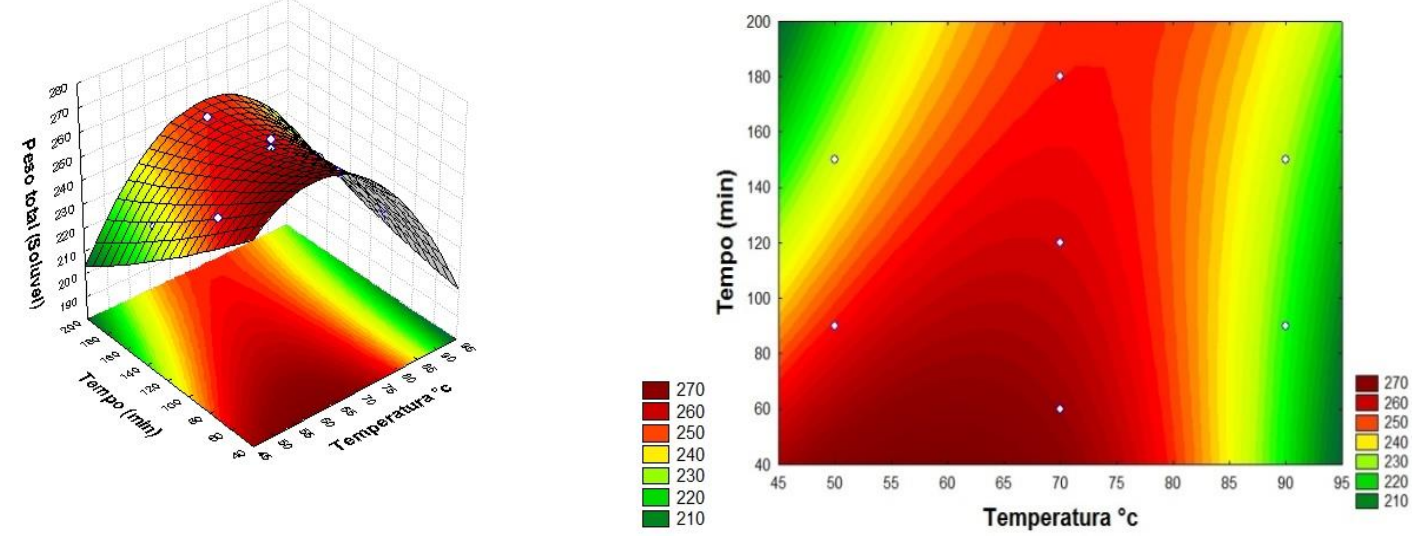

Figura 2: Gráfico superfície de resposta e curva de níveis - Influência do tempo e da temperatura na purificação da fração solúvel do exopolissacarídeo do micro-organismo Rhodotorula orizycola.

Tabela 2: Análise de variância (ANOVA) para purificação do exopolissacarídeo do micro-organismo Rhodotorula orizycola.

TABELA DA ANOVA

\begin{tabular}{|c|c|c|c|c|c|c|}
\hline & SQ & gl & QM & Fcal & Ftab 5\% & R $^{2}$ \\
\hline Regressão & 1770,22 & 5 & 354,0444 & 43,05 & 9,01 & 0,98 \\
\hline Residuo & 24,67 & 3 & 8,222222 & & & \\
\hline Ajuste & 6,00 & 1 & 6 & 0,64 & 18,81 & \\
\hline Erro & 18,67 & 2 & 9,333333 & & & \\
\hline Total & 1794,89 & & & & & \\
\hline
\end{tabular}

FONTE: Autora

\section{CONSIDERAÇÕES FINAIS}

Os resultados mostram que foi possível a obtenção de polissacarídeos a partir dos micro-organismos Cryptococcus liquefaciens (302) e Rhodotorula orizycola (D2T61). Os polissacarídeos estão sendo identificados e serão avaliados quanto a atividade antinoceptiva, antioxidante e anticoagulante.

\section{REFERÊNCIAS}

DINI, C. M. Produção, purificação e caracterização das proteases de Thermomucorindicae-seudaticae n 31 e avaliação de sua aplicação na fabricação de queijo maturado. Tese (doutorado) - Universidade Estadual Paulista, Instituto de Biociências, Letras e Ciências Exatas, 2010.

ERNANDES, F. M. P. G.; GARCIA-CRUZ, C. H. G. Levana Bacteriana: aspectos tecnológicos, características e produção. Semina: Ciências Agrárias, Londrina, v. 26, n. 1, p. 69-80, 2005.

GUIMARÃES, L. B. et al. Influência de diferentes fontes de nitrogênio no crescimento e na produção de EPS pelo fungo Diaporthe phaseolorum var. caulivora. Braz. J. Food Technol., VII BMCFB, São Paula, 2009.

LEHNINGER, A. L. et al. Princípios de Bioquímica. 5. ed. São Paulo: CBL, 2002. MELO, D. L. F. M. Potencial biotecnológico do umbu: perspectivas para o semi-árido. 2005.

SILVA, M. DE L. C. et al. Caracterização química de glucanasfúngicas e suas aplicações biotecnológicas. Quimica Nova. Vol. 29, No. 1, 85-92, 2006.

SOUZA, D. M.; Garcia-Cruz, C. H.; Semina ciênc. agrar. 2004.

SUTHERLAND, I. W. Novel and established applications of microbial polysaccharides.Trends in Biotechnology, Limerick, v.16, p.41-46, 1998. 